\title{
Gender violence in migration: Voices of migrant women in Sicily
}

\author{
ROBERTA T. DI ROSA \\ University of Palermo, Italy
}

\begin{abstract}
Migrant women constitute a growing reality in Italy, also with reference to violence among family members. In particular, violence endured by the foreign female takes on a character of 'dual violence,' the violence experienced within the relationship is supplemented by the violence from the social context, which often isolates her, or even expels her following her 'coming out into the open.' The article presents extensive reflections emerging from the results of research carried out in 2012 in Sicily, aiming to explore the experience and perception of family violence and the possible influence of the migratory experience on changes in the forms and implications of family violence. The reflections emerging from the research are presented to the reader in a form integrating data about the phenomenon with relative scientific material, so as to provide a broader understanding of the dynamics observed and the general phenomena influencing them. In this article the essential features will be dealt with, including the opportunity and risk emerging from contact with the host culture, the role of national or cultural communities, the perception of violence and the inclination to react, and the intergenerational conflict. The final reflections will be derived from these, with regard to possible plans of action and prevention of the phenomenon.
\end{abstract}

\section{Keywords}

Migration, women, family conflicts, gender violence

\section{Introduction}

Over the last twenty years the immigration phenomenon in Italy has grown continually and the number of immigrants is 30 times higher than before. On January $1^{\text {st }} 2014$, the foreign population in Italy, as estimated by the Fondazione Ismu, amounted to over 5.5 million elements, both documented and undocumented. At present, there are 300,000 more female than male immigrants in Italy. According to ISTAT, in 2014 females born abroad numbered 2,591,509 out of a total female population of 31,298,104 units, therefore representing an ever more substantial portion of the population.

Immigration over the last twenty years has assumed a resident character. Considering the amount of new-borns $(78,000)$ and arrivals $(43,000)$, the actual increase seems mainly due to people arriving to join their families. Today this constitutes the main reason for entering Italy. Between 1993 and 2013 there was a 1,328 per cent increase in the number of requests for temporary residence permits (for family reasons). In comparison, the increase in requests for work permits was only 488 per cent. Consequently, there has been an increase in nuclear families. In 1991 there were 235,000 
families consisting of foreigners alone, while in 2014 there were over $1,300,000$. The number of young people under 18 (in Italy designated as minors) has increased accordingly. At the beginning of the 1990s, there were fewer than 100,000 minors, but by 2013 they numbered almost one million $(995,000)$, most of who were born in Italy. The stabilisation of nuclear families has changed the characteristics of the overseas population in Italy. It has also drawn the attention of researchers to issues such as family dynamics during migration, processes of integration and emancipation, relational criticality in shared migration, and family violence. The latter is also a burning issue for Italian families.

The first and only piece of national research conducted into violence against women (Istat 2006) discovered a widespread problem. In 2006 there were 6,743 Italian women (aged between 16 and 70) who had been victims of physical or sexual violence. This amounts to 31.9 per cent of all women in this age group. It is mainly those closest to the women who are violent towards them, including live-in partners, fathers, fiancés, ex-partners, brothers, or sons.

In 2006, 101 women were murdered by their partners, husbands or expartners, and in 2010 this figure increased to 127 (Bartholini 2013: 23). In addition, partners were responsible for 69.7 per cent of rape cases, acquaintances for 17.4 per cent and strangers for only 6.2 per cent.

Domestic violence continues to affect women across the country, as the report of the General Assembly of United Nations shows (A/HRC/20/16/Add.2). This report contains the findings of the Special Rapporteur on Violence against Women, following her visit to Italy from 15 to 26 January 2012. The report explores the causes and consequences of domestic violence.

Unfortunately, it is only possible to estimate the number of foreign women who experience acts of violence. The 2006 national research into violence against women (published by ISTAT in 2006) did not include migrant women (despite the presence of 1,465,8549 officially registered foreign-born females in Italy, out of a total female population of 30,224,823). Data gathered by the Equal Opportunity anti-violence help line was used to estimate this phenomenon. It was found that in 2011, almost 95 per cent of women exploiting the service were foreign-born. 53 per cent of these women reported cases of physical violence (compared to 35 per cent of Italian women). With regard to psychological violence, 18 per cent of cases involved foreign-born women (compared to 12 per cent of Italian women). In both cases, the perpetrator of the violence is usually the husband, live-in partner or fiancé. 
The reports published by civil society organizations that support migrant women also proved useful, in particular the report by the Trame di Terra Association's inter-cultural centre for women. Interviews with women who have used the service for other problems (such as work, difficulties with public services), show that one out of two has experienced domestic violence. The main problem in calculating the true figure (apart from the lack of nationwide research) is closely linked to the difficulties that migrant women (especially first-generation) encounter when seeking to access services for victims of violence. This happens partly because of accessibility, but mainly because of the cultural resistance caused, especially within the women's context of reference. The same difficulties also exist for Italian women.

Little is known about violence against women, whether Italian or migrant. Gender violence has long been neglected as a topic for investigation, and remains a particularly difficult area for the social researcher. This is the case not only for reasons connected to the delicacy of the subject and a tendency for victims to remain silent, but often also because of inadequate research tools and methods of investigation. This means that the figures for violence are often substantially underestimated. It also means that the actual essence of the violence itself is little understood especially in regard to the social, cultural and psychological factors that foster it, the gender models at its roots, the prejudices surrounding it, the relational dynamics in which it evolves, and finally, the motivations and life-projects adopted by the men and women involved.

\section{Literature Review}

Abuse against women is the world's most widespread yet least reported crime (Kustermann 2008: 11-14). It is a phenomenon present in all strata of society and at all levels of education. It has become normality rather than pathology in today's world (Danna 2007). In addition, domestic violence is difficult to characterise in a 'universal' way. In every culture its definition emerges from the concepts and the dominant roles of gender and family. Leaving aside whether it is recognised as such or not, or the variety of ways it manifests itself, the fact remains that violence against women exists in innumerable contexts. These vary greatly in terms of culture, religion and political and social situation, both in developed and developing countries.

As previously mentioned, the phenomenon of domestic violence is still widespread in Italy, affecting both Italian and migrant women. For many immigrant women, violence and discrimination characterise their lives before emigration and may accompany them to their new destination (Di Rosa 2013). Lombardi, following various studies around the world (including those by Armstrong 1998 and Visaria 1999, as cited in Lombardi 
2005: 105) refers to a recurring pattern of events that trigger violence, such as "not obeying one's husband, answering back to scolding and insults, refusing sexual relations, not having meals ready at the usual time, neglecting one's children and home, asking questions about the utilisation of money or about one's partner's female friends, going off without authorisation" (Lombardi 2005: 105).

Opportunities for emancipation (Lavie and Swedenburg 1996) and reordering of gender hierarchies may well improve the power and status of women (Grasso 1996) compared to men. But it is also possible that the asymmetries of gender may remain unchanged and may even compound certain aspects of the subordination of women (Yeoh 2010). Migration brings about changes "both when the family is close at hand and when one's loved ones are far away, given that it involves a rethinking of one's belonging within the traditions and values of the culture of origin" (Tognetti Bordogna 2007: 105). The transition involves tensions and critical situations and the woman often has difficulty trying to integrate the models from her own culture into her personal life (Ambrosini and Abatecola 2010). There is also the risk of discrimination towards the female, as a result of destabilisation of the male role (from the man's perspective), in particular when she works and the man does not. This may subsequently create problems in the equilibrium of the family (Gozzoli and Regalia 2005; Andolfi 2004; Cattaneo and Dal Verme 2005).

The relationship between migrating couples needs to undergo a period where identities and roles are readjusted, in particular those of gender. Separation results largely from the motivational approach towards the plan to migrate (for example, in relation to duration and dynamics of integration). Therefore, the shared life-project may be disrupted because of differences in choices and stabilisation, ultimately made worse by the woman's new, emancipated condition (Viapiana 2011).

The dysfunctional dynamics between men and women within a relationship are often linked to one's own identity crisis when migrating, combined with the difficulties of trans-acculturation of gender models (Yeoh 2010). The arduous daily challenge lies in "finding a balance via a variation in one's role, whilst maintaining at the same time one's own ethnic identity" (D'Atena 2008: 91).

As a result, tensions tend to explode at the level of 'family' and 'cohabitational unity'. Both of these are areas where the individual participants are continually reshaping their roles and responsibilities within the everchanging circumstances of the family context. "Marital violence is unleashed against the background of a situation full of economic problems caused by difficulties in finding a job, together with the reduction of 
confidence in their own identity that many immigrant men experience" (Balsamo 2003: 37). A case where the foreign female seeks help while lacking a temporary residence permit renders the aid process even more difficult (Van der Troost and Vial 2008: 299-310). The foreign women find themselves with first-hand experience of all the contradictions of a society that, instead of welcoming them, struggles to integrate them and from which they often feel excluded. Similarly they frequently encounter (and in dramatic fashion) divergences with their existing point of reference, the world of values possessed and defended by their original family, which they themselves no longer consider as part of their own new world (Tommasi 2007).

The experience of migration alters the linearity of inter-generational relationships with regard to both moral and cultural values It is an event or experience of 360-degree change as regards the family context (Scabini and Rossi 2008) and the living environment (Yeoh 2000). Comparison with the host country brings to mind one's previous existence, often generating a rethinking of one's adhesion to traditions and values in the culture of origin (Ambrosini and Abatecola 2010). The ensuing tensions, which are particularly acute in children's pre-adolescent and adolescent phases (Andolfi 2004), end up as extremely diversified attitudes. These may range from a radical and rigid return to one's original cultural models, to a laissezfaire impotence because one lacks the necessary tools to define a model of "being suitable" (De Cordova and Inghilleri 2014: 4).

Second generation adolescents are subject to strong expectations and pressures from the family in different areas of their lives (Tognetti Bordogna 2008). This obviously exposes them to a greater risk of victimisation. The relationship between generations, which for many foreign parents has been represented by an image of vertical asymmetry, can be seriously challenged by the disorientating proximity and symmetry of roles between adults and children. Because of the tension that derives from these choices, children become "true foreigners in the eyes of their relatives and probably to themselves" (Gozzoli and Regalia 2005: 155).

In inter-generational dynamics, the comparison between different organisational models also concerns difference of gender, and in particular, the role of the woman in society (Mariti 2003). This comparison often erupts into tension and conflict with regard to children's upbringing in general, and that of young girls in particular (Gennari and Di Nuovo 2011).

The issues that are most emblematic of the difficult situations in which young immigrants might find themselves are the two customs, considered to be 'nefarious traditional customs', that invade their freedom and integrity to the greatest extent. These include underage marriage, arranged/forced 
marriages, and female genital mutilation. These forms of abuse are passed down through tradition and custom and represent symbols of honour and virtue, which a woman is expected to carry forward. Opposition to these customs would, in many cases and in various countries, entail heavy sanctions, and might even result in death.

Although these phenomena are still largely well concealed, mediators, cultural operators and social assistants are receiving increasing numbers of pleas for help from foreign women (Danna 2010). For those working in social services, the handing-on of relational patterns (between men and women and between generations) acquires today an ulterior and, to a certain extent, greater significance in migration, where family dynamics become stronger both as a system of gender building and as a system of safeguarding one's belonging. (Morrone and Vulpiani 2004). Polarisation is typical of this kind of family conflict, in terms of moral (and therefore, to all effects, cultural) values, and needs to be avoided absolutely. There is a risk of exasperating this confrontation, resulting in an authoritarian rigidity in the older generations and an exacerbated consolidation of traditionalism (Markova 1993).

\section{Presentation of research}

We begin by acknowledging extensive literature on this subject, with two aspects chosen as a starting point for the research. Firstly, both the definition of any given behaviour, such as violence, and its condemnation are the product of cultural belonging and a social context of reference with the perception of its 'acceptability', on the part of women who depend on this definition. Secondly, every existential change affects the lives of one or more family members, especially if the entire family has shared the migratory experience. This has effects on the perception and assessment of the behaviour carried out and can therefore also influence the reaction of subjects (participants or witnesses) who are involved in the episodes of violence.

Starting from these assumptions, the research moved in three directions:

Investigating the changes in relational dynamics triggered by the migratory experience, together with redefinition of identity and belonging of the individual subjects.

Verifying whether, and to what extent, migration alters the perception of 'acceptability' of violence on the part of migrant women and, at the same time, whether, and in what way, it may influence the degree of 
acceptance/refusal and the possibility of taking one's distance and/or reporting it.

Understanding what, in terms of "expressional shortcomings or, on the contrary, relational abundance", can lead to violence becoming the actual binding element on which male-female relationships are based within stable unions and among generations (Bartholini 2013).

The research ${ }^{1}$ was carried out through hermeneutic ${ }^{2}$ interviews with migrant women ${ }^{3}$ (singled out by health and social services) who, at the time of the interview, had managed to sever the relationship and distance themselves from the context where the aggression had taken place and build a new life elsewhere.

The interviews provided material regarding life-experiences (including violence), migratory plans and relations with the host society, while at the same time there was an attempt to reconstruct not only the interviewees' own representation of violence in general, but also the actual image shaped by personal experience as victim and/or witness.

The material emerging from their life stories will be presented in the subsequent paragraphs, devoted to the recurring themes recorded. These include the risk and the opportunity for familiar relations in migration, the experience of violence in their lives, its perception according to their native culture and the points of contact/distance with the values of the country of migration, the women's propensity to react and the specificity of secondgeneration experiences.

\section{Opportunity and risk factors linked to migration}

The stories that we heard confirmed how migration might render relationships within the family more fragile. Migration constitutes a clear risk factor for potential marriage failure and poses the parent problems with the redefinition and reformulation of family ties and internal equilibrium. The transformation of gender roles faces numerous obstacles, including tensions due to reorganisation emerging between man and woman in the country of migration. These will be subject both to strong pressure from the reference group and to regulation from the family that has remained in the country of origin. Tensions can increase when the wife (but also the

\footnotetext{
1 PRIN 2008 Research - Palermo Unit, regarding "Repeated abuse in close relations of intimacy. An evolving model of redefinition of identity" as part of the national research "Abuse in intimate relationships: generations, gender and intervention policy" co-ordinated by Consuelo Corradi, LUMSA, Roma.

${ }^{2}$ For an explanation about hermeneutic interviews see Appendix 2.

${ }^{3}$ For information about interviewed women see Appendix 1.
} 
daughters) behaves in ways that differ from those acknowledged as valid in the culture of origin.

Migration also exposes the individual to considerable change, and presents a challenge to adapt that is not easily met. Difficulties are represented by integration, uncertainty about the future, the separation of families, difficult material conditions of life, and different values and cultural models.

Although violence towards women is transversal with regard to space, time and social conditions, it may be noted that for migrant women involved in our research, whenever the difficulties for the male/husband increased, so does the physical abuse towards the female, both within the family and in their country of origin, because of their "multiple and multiform discriminatory" condition (Macioti et al 2006: 30).

From our study it emerged that migrant women may experience different forms of violence. If we wish to summarise 'typical' forms of abuse as experienced by them, it is evident that some forms are more closely linked to cultural values, such as the following: the family.

'Punitive' corporal punishment in cases of disobeying the head of

Enforcement of sexual relations with spouse/partner.

Downgrading to a state of slavery in the husband/partner's family.

Serious or complete restrictions on freedom of choice in terms of personal life (for example of study, choice of husband, work).

Subjugation to the male figure, implemented through relegation of the woman to a state of total dependence and isolation from her external context.

The man having control over the family's income including that of the woman herself.

Permanent physical damage (genital mutilation).

With regard to relational factors, emphasis is placed on the dysfunctional couple relationship, including the presence of difficulties in integration, identity crises or contrast between gender and familiar models. Notably, some of the families of women interviewed point to episodes of domestic violence that are often exacerbated by other problems such as men's alcoholism, addiction and/or depression. 
I split up with him because he didn't want to go to work; he drank too much; then he'd beat me up continually; it was always chaos with me going out to work as a seamstress in a factory. If he didn't smoke his hashish, wow what happened.... it was terrible, awful what he did. He'd beat me and he had to have it (....). I've suffered so much; look he's left scars on my face (....). I couldn't go on and bear all this, because he'd also beat the kids (....) (Morocco, aged 59).

Two categories of risk factor can be identified from the stories heard. Firstly, generic factors, linked to the psycho-cultural events of the migration, to anomalous behaviour in relationships, consequent to situations of sociosanitary marginalisation that regard the poor conditions of life, housing conditions (Di Rosa 2008), economic difficulties, the low quality of working experience, frustration arising out of daily subjection to external discrimination and exploitation, or "stress from trans-culturalisation" (Mazzetti 2003: 83). In addition, there exist specific risks linked to more personal experiences, such as the difficulties encountered as both individuals and couples, the fear of the emigration project failing, the implications that "the success or failure of the project may have on the future of the family as a whole" (Sall 2001: 142) and, lastly, comparison with models of couples and parents other than one's own, and more specifically, "the loss of one's points of moral reference" (Ghiringhelli 2010: 21). In particular, it is the inversion of breadwinner roles that heightens tension and, because people are so stressed that they cannot handle it adequately, it then leads to manifestations of violence.

Me and my husband were living in Pordenone (...) he had problems at work; we didn't get on; we'd argue all the time and one day he started slapping me, because I was angry and told him what I thought and after that, for a month, he'd slash me on the belly, he tied my feet together and I couldn't run away (Ghana, aged 37).

In this sense, it emerged from the interviews that experiences of violence function to re-establish the balance of power and authority within the family nucleus, even more so in cases of family nuclei with traditions that make provision for the use of violence in re-ascertaining family authority and equilibrium. For the male, the sensation that he is losing the dominant role that he enjoyed in his country of origin, plus the fear of no longer being acknowledged as the holder of power and the head of the family, provokes violent attitudes towards the women and often to the children as a last attempt to hold onto his traditional role and power-base.

\section{Cultures, communities and violence}

Whereas in Italy a justification for violence as a consequence of male power is nowadays quite insufficient, for many other countries and cultures the patriarchal family remains the model that principally generates and breeds violence. Whatever form it takes, violence presupposes the woman to be in a subordinate role to the man. In some countries the inequality is explained 
as possession of inferior civil rights on the part of the woman, while elsewhere, although law endorses equality, traditions and customs of a patriarchal nature perpetuate a cultural model that debases women and envisages their subjugation by men, who believe they can exercise arbitrary power over them. This was confirmed by the women interviewed through the narration of their experiences.

I often walk on the streets alone, without anyone accompanying me, even when it's raining, I go back home and have to cook, because there's never anything ready for me; then I have to do the shopping, I have to see to everything, and he and his mother are never happy with what I do. Always against me, bad-mouthing me. He's got a scooter and never gives me a lift; he only goes out with his mother and takes her wherever she wants (Sri Lanka, aged 39).

We are still a long way from the removal of those cultural systems that continue to condemn women to a confined domestic space where their opportunity for expression is delineated by sexist models of social, cultural, political and religious organisation. However, migration, with its power to transform people and their relationships, also lessens the rigidity of this model, drawing it closer to the modern world (Schiavon 2011).

For the women interviewed, the experience of abuse was not 'unexpected' or exclusively linked to the intimate environment of the family. Rather, it was viewed as a constant risk, a scenario that lay behind every action performed both within the family and outside it.

When they're subjected to violence, women have to put up with it, keep quiet. See what happens at home: everybody's at war, while I keep quiet and pray. The woman has to be kind, she has to hold fast and be patient. She mustn't hit anybody (....) If the woman is beaten by her husband, she has to be kind. Understand? The wife has to be kind, so nobody beats her any more (Sri Lanka, aged 39).

The idea that the husband has the right to beat up a woman or to threaten her physically is deeply rooted in many societies and it is not rare for women themselves to justify, under certain conditions, a given degree of violence.

The man doesn't usually beat the woman if she hasn't done anything wrong. The wife might happen to say something bad to her husband because she's angry and the husband, in a fit of rage, might start hitting her. This isn't fair but it can happen. If a woman is married she mustn't go out and about alone too much. If the wife trusts her husband and shows affection he will never use physical violence and treat her badly (Ghana, aged 37).

Moreover, women are not always in a condition to react, due to having already experienced abuse in childhood in their country of origin and thus accepting it as 'normal' or regarding it as routine. 
I know of my cousin who has two kids by another man and her present partner behaves badly towards her with his bad language and physical actions, and also with her kids. But the problem is that she doesn't understand that he isn't the only man on the planet and doesn't have the courage, the strength to leave him or report him. He happened to beat one of her kids, who is now 7, and the kid ended up in hospital with problems to his head (....). I don't think she has ever reported him, or maybe, once she pretended to, because my mother told me that they met in hospital and she was there because he had beaten her up and had torn out one of her nails (Russia, aged 26).

Furthermore, it appears that the women tolerated the abuse because it was never questioned within the community to which they belonged.

The Muslim culture in Senegal doesn't let the law enter the household, because it's considered a disgrace; it's better to work everything out with the families and if they don't manage to work it out, you can resort to the law (...). In our country there aren't many cases of women reporting; everything is resolved within the family (...) (Senegal, aged 43).

It must be underlined that the respondents identified physical abuse most readily as such, and, less so, sexual assault, psychological abuse or economic abuse.

There's this friend of mine from Nigeria who is still getting maltreated by her husband. Once he even stabbed her in the leg. She called the police, but as soon as they arrived, she said it was an accident and not her husband. (...) There are many men from Nigeria who are violent, but not all. There are many men who think it normal to lay their hands on their wives. It's the women who don't talk about their lives to strangers (....). And they don't rebel, for them it's normal (Nigeria, aged 41).

In the host country, the community, consisting of their fellow countrymen/women, acts as the social and cultural reference point for individuals. However, it is interesting to underline that the community plays an ambivalent role in cases of domestic violence, as the respondents' stories show us. On the one hand, culture has the function of being a guarantor of cultural identity and therefore often exercises pressure on women to adhere to behaviours that belong to their society of origin (thus legitimising the behaviour of husbands who are maltreating them). Opposing the community by reporting the husband in this case would mean negating one's own roots and experiencing disorientation with regard to one's own identity, increasing the woman's anxieties and fear for her own future and that of her children.

In Senegal now, if a woman reports her husband she is protected, but the problem is that women never report anything. In Senegalese culture there is a saying that goes: "everything a woman does against her husband will return against her children", and "A woman's work is her child's dinner", in the sense that all the things a wife does against her husband, like not cooking well, taking his money, having him go to prison, insulting him, beating him, rebelling etc., all this will have repercussions for 
her child. This belief is rooted in all Senegalese women, and that's why they don't report anything (Senegal, aged 38).

On the other hand, by consulting a community of fellow countrymen/women, the couple might be able to limit the negative consequences of potential family tensions.

If there is a real danger to a woman's life, because the husband is threatening to kill her, then it is right to report it. But if it's only for the beatings, no, this doesn't mean anything. In African culture, no woman reports anything. If anything, a relative or a trusted acquaintance will intervene and hear both sides and then report what exactly happened. It is this person that can resolve the problem and that's why there is no need to resort to reporting to the police (Liberia, aged 21).

The community, in fact, offers certain advantages for mediation in cases of family disputes, offering the couple concrete support (above all from women), which might take the form of an exchange of services or direct control over the violence. To a certain extent, the community of reference may take the place of the family left behind in the home country, the family that, in the case of violence, would have had the power to intervene in controlling the husband's behaviour and "absorbing tensions" (Balsamo 2003: 37).

A woman shouldn't report her husband immediately, if he has been beating her. She should first try to talk to him and if that doesn't work she should talk to his father and then she can report her husband, because she can always go back to living with her father. The problem is when one's family is a long way away...(Morocco, aged 23).

In fact, the cases where the couples do not have a community of reference are more serious, as the fragility or absence of a network of relations or community members is directly proportional to the isolation and withdrawal into itself of the family unit, which in turn favours the instigation and worsening of the problems in the couple's relationship.

If a man beats his wife or hurts her and although she tries to talk to him he continues, it is better to leave him and, if she can, go back to her parents' house. I believe that it is not right to report to the police (....). It's the way men are; they change. I don't know why, but I don't believe in reporting to the police, in beating and bad-mouthing (Eritrea, aged 33).

In the opinion of almost half of the women interviewed, the distance from their family of origin and the consequent absence of social control is a major problem because it means a lack of mediation of an extended family. This isolation of the couple may lead to an even more rigid codification of the male and female roles, which would also "manifest itself more frequently and with no filter on the abuse" (Sall 2001: 144).

\section{Conflicts and violence between generations}


According to the interview responses, another highly significant issue is that of change in parent-child relationships, which occurs as a result of rootedness in a country with a different language and culture. The younger women interviewed, who had arrived in Italy in their infancy, talked about their personal difficulties in finding a balance between their lives and family rules and those of the outside world. On the other hand, the interviewees arriving in Italy as adults and with pre-existing family relations, confirmed, from a directly opposite point of view (that of the mother) the existence of these inter-generational difficulties. For the former, the issue consists of reconciling their culture of origin (continually perpetuated by the family) with the culture of the country of residence, which is experienced daily in their relationship with their peers.

The latter, on the other hand, often consider themselves guarantors of family identity and the group's traditions. They feel responsibility for the community's cultural heritage, to such an extent that they often become more assiduous followers of their faith and its prohibitions than they were previously in their country of origin, something which they then also impose on their children (Saint-Blancat 1995: 72).

Comparisons between two or more moral systems are inevitable and quite often constitute a reason for deep tensions regarding integration and marginalisation. After experiencing the moral standards of the host country it is not simple to hand down the ethics of one's own culture from one generation to the next. The feeling of threat to one's own identity may be perceived as an external issue created by the host society, but also as internal, via the calling into question of the family's established norms on the part of the children.

\footnotetext{
In 2007, a friend of mine reported her father for beating her, because he didn't want her to go out and have a boyfriend. I was present throughout this period personally and I encouraged her to rebel and when she left the social centre here in Palermo, I put her up at my house and then she and her fiancé decided to move to Rome (...) it isn't true that they do it because of their religion, because my husband is also very religious, but he doesn't agree with all these things (Tunisia, aged 25).
}

The media reports increasing numbers of violent stories, often involving young immigrant women. These are often caused by strong clashes with their families, caused by "the generational gap established in parallel to the process of migration" (Schiavon 2011: 47). As recounted by the young women interviewed, in the second generation it is the female immigrant who often suffers when finding herself caught between two approaches to family roles and understanding the differences between genders. Behaviour common to all teenagers (such as returning home late, or wearing make-up) defies the rules of the family. 
My brother, who was always a bit like this, never let me do anything... He controlled me too much and he told me not to go here, not to go there. Even though I'm older, he wants to adopt the male role and give orders. So he'd tell me that I couldn't go out or do this and that (Morocco, aged 23).

Violent and dramatic reactions may also result, such as running away from home, suicide attempts, sexual relations and underage pregnancies, involvement in abusive relationships (given the need for strong affective bonds in order to break away from the family). The actual possibility of seeking external aid for support against the constraints imposed by their family of origin is rarely contemplated.

But if these acts of violence are carried out by the father or the brothers it is better to try and talk to them and not report them. Otherwise the woman will find herself alone, not knowing where to go and so it's always worse. I've met women who were beaten by their fathers, they reported them and ended up with more problems because the father wouldn't speak to them for the rest of their lives, he'd go to prison, the mother and brothers would no longer speak to her and she finds herself on her own and homeless. Unless you find a husband who is better than your own family, somebody who can always welcome you and is better than your relatives (Morocco, aged 24).

In most cases the victims remain oppressed by their dual role, trapped in situations of abuse and violence, hidden within the family or community of origin, and thus difficult to single out.

Violence, for me, is also something that a woman can suffer at the hands of a father or brother; this is family violence and a woman should also report it in these cases. The fact is that many women don't report their fathers or brothers because they're afraid of remaining on their own or they're afraid they won't know where to go (Ukraine, aged 27).

The social structure of communities of migrants living in certain areas and coming from particular regions or social classes in their country of origin, continues to endorse the legitimacy of parental choice in arranging their children's marriages, occasionally ending in actual imposition.

I got married when I was 20. I was very young whereas he was 44 . Now he's old, with a walking stick, but now he's married another woman, younger than me. My family chose him. I was forced to marry him. When I saw him for the first time I immediately realised he wasn't the man for me. When his family spoke to mine, they showed a photograph in which he was much younger and they said he worked in a factory, but it wasn't like that at all. He wasn't working. If something came up, which it rarely did, he didn't want to work because he wasn't used to it (...) My wedding day was awful. I was crying in front of my family. I was acting crazy and kept saying to them: “I don't want him. I don't like him. I don't want to go with him". But they just said: "Keep quiet, keep quiet" (Morocco, aged 59).

This choice is often challenged by younger generations, who have grown up in a cultural environment where sentimental relations are not determined 
by the family but by the individuals involved. Actually, the imposition of a marriage affects both young men and women, but it happens far more often to females. Daughters are subjected to greater control than sons in the family of origin. Forced marriage persists not as a phenomenon in itself but as a specific ideological aspect and a means of controlling women/daughters. In fact, the imposed marriage cannot be considered as an isolated phenomenon, as it always occurs in nations or in social contexts where many other forms of restrictions on female liberty exist.

In this case too, it is the migratory experience that intervenes to provoke a transformation sparking off another transformation and a generalising comparison with other socio-cultural models. Among the women interviewed, those who have lived there for a large part of their lives have the perception that arranged marriages are increasingly felt to be forced marriages. As a result they are increasingly rejected, thereby amplifying the conflict between generations.

The same can be said for Female Genital Mutilation (FGM), a traditional, ancient and deep-rooted custom. In these cases, gender violence is carried out on the woman by other women as agents of patriarchal values. They are women who, through maltreatment, express and reinforce an asymmetrical social order, taking on the role of the 'good abuser' believing that this action might be in the girl's interests, and that in carrying it out they are applying legitimate authority at the cultural and religious level (though the practice might have been severely condemned by various countries at the international level).

The results of our research are in line with other surveys carried out in Italy (Scoppa 2012). We are witnessing a change in perception with regard to this custom, with a decline in this practice from one generation to the next. Not all women view it in the same way, and it is no longer a necessary practice for all.

In Senegal FGM is no longer carried out because we are free now and the practice has stopped. It hasn't disappeared completely but it's gradually being eliminated. This is important because these mutilations have extremely negative consequences for women's health. They are forms of violence (Senegal, aged 43).

This phenomenon is by no means disappearing. The dilemma about the future of their daughters torments many foreign women living in Italy. The change, however, is not automatic, but is linked to a positive integration experience after migration. If the mother's experience is negative, this might lead to her shutting herself off within her own culture, viewed as a refuge from contamination and contact with models and values that are "alien and, as such, dangerous" (Scoppa 2011). Consequently she may wish to follow the rules and customs of her culture of origin for her own daughters. As has 
emerged in the interviews, women who are sufficiently integrated in the host country have already distanced themselves from practising traditional rites in order to reaffirm their own identity, both in Italy and in their country of origin. In particular, it appears that women with a higher level of education have started to distance themselves from this custom. On the contrary, recourse to this practice (instead of its elimination) can be bolstered by obstinacy from the first generations as a result of failure in their migratory project, or frustration with the impossibility of integration, which may lead to entrenchment in traditional cultural models as the only bedrock defining identity and belonging.

\section{Perception of violence and inclination to react}

One of the problems with gender violence that renders the search for ways to stop it more difficult, is that in many cultures it is accepted, tolerated and justified, as amply demonstrated in the report edited by Spinelli (2010) on customs involving gender violence around the world and confirmed by our interviewed women.

Reporting is awful because all the family is ruined. I've met lots of girls who have reported a father or husband and have then had only problems, being thrown out of the house. Because if I report; then I lose my husband. And if I'm not working it's even worse. Even when the woman is working, if she has kids, they will always scold her because she had their father sent to prison. And this is so, even if the woman has done a lot for her kids, the blots remain. That's why it's better to avoid reporting and I'll repeat it again, it must always be the woman who puts things right (Morocco, aged 23).

The respondents identified the following main causes of vulnerability:

- The premature experiences of violence within one's own community.

- $\quad$ Poor or non-existent command of the language of the host country.

- Inadequate access to appropriate work and lack of guaranteed regular income.

- $\quad$ Limited knowledge of one's rights.

Limited social contact and diminished contact with the family and original community of belonging, especially in societies where the extended family plays an important role in the couple's internal relationships, seem to increase the probability that the violence may continue and for quite a long time.

The problem was that I didn't speak Italian and I was never able to speak about it to anybody for many years (Ghana, aged 37). 
Other risk factors include age, education, ethnicity and legal status. Furthermore, and, in certain cases, taken together, they reduce the capacity of immigrant women to protect themselves against possible situations of maltreatment or violence. Among significant elements at the level of social policy, there emerges from the interviews (apart from poor relations with the external world and difficulty in communicating with the world outside) a low level of faith in Italian services in seeking a real solution to the problem, an element that constitutes a significant obstacle to recourse to anti-violence services.

It's better to leave things as they are, it's not worth reporting. Because then, there are too many documents and all this merely to obtain a sheet of paper. He won't change, and at home it's the same old story (Sri Lanka, aged 39).

Synthesising the general feelings of the respondents gives one the impression that the host country is seen as distant and relatively ineffective in guaranteeing real protection for anybody wishing to report, in the face of much stronger and deep-rooted dynamics within the community. More than one of the interviewed women stressed how, in these conditions, it is really hard for a woman to make a break with her system of reference. Furthermore, women's altered perception of 'normality' of violent behaviour might actually boost the phenomenon of domestic violence, rather than help eliminate it.

Among respondents, the voluntary acceptance of oppression seemed to emerge as a significant fact with the greatest semantic importance. At the same time, it was evident that the experiences of violence seemingly had the function (in the intentions of their perpetrators) of re-establishing, within the family nucleus, the balance of power and authority (all to the detriment of women).

In this relational dynamic, a different perception of the violence undergone over a long period and, above all, by women from the same countries of origin, is seen as 'acceptable'. In other words a range of reactions, attitudes and alternatives represent the 'scores to be settled' and tolerated as an integral part of the challenges of migration and not as distortions in the relationship, but as unfortunate 'collateral damage' deriving from external tensions, and connected to the context of incorporation (or marginalisation) in the host country.

\section{Uprooting violence against women: a cultural revolution}

Domestic violence, especially from the perspective of the migrant female, inherently points towards the need to reconsider the topic as a subdivision of the more general and universal problem of male violence against women and the implied imbalance of power between the sexes. 
In the light of the responses, a determining element seems to be the fact of belonging to highly traditional cultural models or to other more modernised ones (regardless of nationality). Nowadays, many cultures co-exist in most nations, and these may range from a rather orthodox affiliation to traditional systems to established forms of modernised civil society. Consequently, it seems overly risky to try to single out those nationalities that are most affected by the phenomenon as a result of cultural characteristics.

Above all, a new way of regarding immigrant women (both by the host country and by the women themselves) needs to be contemplated. They should no longer be seen simply as "oppressed, exploited losers, since they are incapable of escaping their family and the cultural ties of their country of origin and since they are linked to a marginalised social condition in the host country" (Vicarelli 1994: 7). Instead they could be seen as women who "in their daily lives show themselves to be capable of an autonomy and an identity that is not that of their past, but neither is it the one desired by western women" (Vicarelli 1994: 9).

It is commonly accepted that personal identity usually has its roots sunk deep in one's original community. A crucial element in one's identity is certainly constituted by one's original culture of belonging, therefore distress may be caused by the absence of one's fellow countrymen/women who might provide one with an image of oneself, or, from disorientation arising out of the subject's reconfiguration of his/her identity. As a result, the immigrant might find him/herself actually beginning to 'see' him/herself in a new image conveyed by another person (Sacchetti 2007).

In any firmly entrenched social context, people will often hesitate to acknowledge a newly arrived identity and the values it brings, and will probably not even be open to negotiation about it. If anything, the previous context may repudiate the new identity completely. If one distances oneself from one's own cultural models as points of reference, and moves into a context that one does not know, one will often undergo, in the sphere of these relations, a process defined as "uprooting of oneself" (Remotti 1996: 54). This may generate bewilderment and suffering typical of the migrant condition.

In the light of all this material, it can be stated that the critical situations linked to migratory paths and the migrant's incorporation into Italy as a country, may actually exacerbate violence within the family nucleus, as a consequence of the resultant re-styling of identity and culture, while causing increased tensions within relationships. 
There emerges a clear need for experts to re-interpret this new scenario according to varieties of culture, and to 'decipher' the experiences by comprehending the system of symbols and values at its root. It is necessary to monitor the various stages of the modernisation process that so-called 'backward' cultures are also launching, albeit sometimes in forms that are not easily comprehensible by western culture. "A need to know and understand that has nothing to do with a logic of acquittal and even less with sharing practices that violate the body, sexuality and freedom of women" (Alessi and Bodelon Gonzalez 2011).

\section{Conclusions}

Violence undergone by migrant women points us in the direction of the complex relationship, slowly unravelling in our society, between universalism and differences (of gender, culture, religion). We therefore need to go beyond the interpretation of 'we/they' with its connotations based rigidly on our most deep-rooted convictions, and to move towards a pluralistic society where one might obtain citizenship, identity and composite models and where all the dysfunctional dynamics of integration might receive care and attention, with the ultimate, common goal of creating a transcultural community.

It therefore seems essential to tackle this abuse against women who migrate, not only to defend the rights of passive victims, but, above all, to confront this misery and programme positive responses to it, via actions geared not only towards women, but also towards men who are undergoing the existential upheaval of being 'somebody else, somewhere else'. It is necessary to draw attention to the distress of migrants (men and women, adults and young people) when reconstructing personal and family equilibrium in contexts very different from their country of origin.

Only by insisting on a policy of respect and attention can we promote a real solution to the problem of domestic violence. To really oppose old/new forms of abuse, it is essential to go beyond the merely repressive perspective of condemnation and involve the community of origin, as a fundamental source of help and support.

\section{References}

Alessi A and Bodelón González E (2011) Rapporto IRIS: Violenza contro le donne nei contesti migratori di Italia e Spagna: conoscenza e percezione delle pratiche tradizionali dannose nei sistemi socio-sanitari. Palermo: Progetto IRIS.

Ambrosini M and Abbatecola E (2010) Famiglie in movimento. Separazioni, legami, ritrovamenti nelle famiglie migranti. Genova: Il melangolo. 
Andolfi M (2004) Famiglie immigrate e psicoterapia transculturale. Milano: Franco Angeli.

Balsamo F (2003) Famiglie di migranti. Trasformazione dei ruoli e mediazione culturale. Roma: Carocci.

Bartholini I (ed.) (2013) Violenza di prossimità. Milano: Franco Angeli.

Cattaneo ML and Dal Verme S (2005) Donne e madri nella migrazione. Prospettive transculturali e di genere. Milano: Unicopli.

D'Agostino M (2009) L'identità culturale e la condotta criminosa nei rapporti intrafamiliari. Available at: www.personaedanno.it [accessed: 22.09.2014]

D'Atena P (2008) La famiglia nell'evento migratorio. In: Schimmenti V and D'Atena P (eds.), Incontrarsi nelle differenze. Percorsi di integrazione. Milano: Franco Angeli, 91-103.

Danna D (2007) Genocidio. La violenza contro le donne nell'era globale. Milano: Eleuthera.

Danna D. (2010) Per forza, non per amore, i matrimoni forzati in EmiliaRomagna: uno studio esplorativo. Bologna: Trama di Terre.

De Cordova F and Inghilleri P (2014) Il corpo migrante tra cambiamento culturale e processi di agency: una lettura delle mutilazioni genitali femminili. In: Mazzara B (ed.), Spazi interculturali: trame, percorsi, incontri. Milano: Unicopli.

Di Rosa RT (2008) Abitare, lavorare, vivere: l'intreccio esistenziale della precarietà migrante. In: Grasso M (ed.), Migranti tra flessibilità e possibilità. Roma: Carocci, 220-242.

Di Rosa RT (2013) La prossimità alla prova delle migrazioni: forme e definizioni di violenza nella esperienza delle donne migranti. In: Bartholini I (ed.), Violenza di prossimità. Milano: Franco Angeli.

Gennari M and Di Nuovo S (2011) L'incontro con l'altro: migrazioni e culture familiari. Strumenti per il lavoro psicologico. Milano: Franco Angeli.

Ghiringhelli B (2007) La violenza e le donne immigrate in Italia. In: Tommasi B (ed.), Donne italiane e straniere maltrattate in famiglia. Milano: Provincia di Milano, 19-29.

Gozzoli C and Regalia C (2005) Migrazioni e famiglie. Percorsi, legami e interventi psicosociali. Bologna: Il Mulino. 
Grasso M (1996) Donne senza confini. Torino: L'Harmattan.

Kustermann A (2008) Un approccio integrato per migliorare gli ospedali. Come renderli più presenti nella difesa delle donne contro la violenza. In: Morelli, F. (ed.), Le donne immigrate in Italia. Salute, tutela, diritti. Roma: Osservatorio Nazionale sulla Salute della Donna, 11-14.

Lavie S and Swedenburg T (1996) Introduction: Displacement, Diaspora and geographies of identity. In: Idem (eds.), Displacement, Diaspora and geographies of identity. Durham: Duke University Press, 1-26.

Lombardi L (2005) Società, culture e differenze di genere. Milano: Franco Angeli.

Macioti MI, Vitantonio G, Scannavini K and Persano P (eds.) (2006) Migrazioni al femminile. Identità culturale e prospettiva di genere. Macerata: EUM.

Mariti C (2003) Donna migrante. Il tempo della solitudine e dell'attesa. Milano: Franco Angeli.

Markova I (1993) Le problematiche intergenerazionali nelle famiglie migranti. In: Scabini $\mathrm{E}$ and Donati $\mathrm{P}$ (eds.), La famiglia in una società multietnica. Milano: Vita e Pensiero, 191-212.

Mazzetti M (2003) Il dialogo transculturale. Roma: Carocci.

Morrone A and Vulpiani P (2004) Corpi e simboli. Roma: Armando.

Remotti F (1996) Contro l'identità. Roma: Laterza.

Sacchetti G (2007) Che cosa sono le mutilazioni genitali femminili (MGF)? In: Tommasi B (ed.), Donne italiane e straniere maltrattate in famiglia. Milano: Provincia di Milano, 15-19.

Saint-Blancat C (1995) L'Islam della diaspora. Roma: Ed. Lavoro.

Sall Y (2001) Traumi, maltrattamenti e violenza sessuale nelle donne straniere: esperienze nel Centro di Soccorso Violenza Sessuale di Milano. In Castiglioni M (ed.), Percorsi di cura delle donne immigrate. Esperienze e modelli di intervento. Milano: Franco Angeli, 125-156.

Scabini E and Rossi G (eds.) (2008) La migrazione come evento familiare. Milano: Vita e Pensiero. 
Schiavon A (2001) Le doppie colpe di Eva: la percezione del fenomeno della violenza di genere tra le donne immigrate. Rivista di psicodinamica criminale $4(3), 23-45$.

Scoppa C (2011) Al fianco delle donne africane verso l'abbandono delle mutilazioni genitali femminili/escissione. Conoscere per prevenire. Roma: AIDOS.

Spinelli B (ed) (2011) Rapporto Ombra. Roma: Coordinamento CEDAW.

Tognetti Bordogna M (2007) Famiglie e processi migratori. In: Idem (ed.), Arrivare non basta, Complessità e fatica della migrazione. Milano: Franco Angeli, 84-107.

Tognetti Bordogna M (ed.) (2008) Ricongiungere la famiglia altrove. Strategie, percorsi, modelli e forme dei ricongiungimenti familiari. Milano: Franco Angeli.

Tommasi B (ed.) (2007) Donne italiane e straniere maltrattate in famiglia. Milano: Provincia di Milano.

Ulivieri S and Biemmi I (eds.) (2011) Storie di donne. Autobiografie al femminile. Milano: Guerrini e Associati.

Van Der Troost A and Vial S R (2008) Violence in relation to (im)migrating women in Europe. Athenea Digital 14, 299-310.

Viapiana S (2011) Donne e madri nella migrazione. Antrocom Online Journal of Anthropology, 7(1), 83-91.

Vicarelli G (ed.) (1994) Le mani invisibili. Roma: Ediesse.

Yeoh BSA (2000) Donne in emigrazione. In: Battistella G (ed.), Migrazioni. Dizionario socio-pastorale. Milano: Edizioni San Paolo. 